M. Klimczuk-Kochańska, A. Klimczuk, Innovation in Food and Agriculture, [in:] P.B. Thompson, D.M. Kaplan (eds.), Encyclopedia of Food and Agricultural Ethics, Second Edition, Springer,

Dordrecht 2019, pp. 1635-1641, https://doi.org/10.1007/978-94-007-6167-4 628-1.

\title{
$\underline{\text { Innovation in Food and Agriculture }}$
}

Andrzej Klimczuk

Collegium of Socio-Economics, Warsaw School of Economics, Warsaw, Poland

Magdalena Klimczuk-Kochańska

Faculty of Management, University of Warsaw, Warsaw, Poland

Keywords: Agricultural technology; Biotechnology; Food additives; Food packaging; Food processing

\section{Introduction}

Innovation means change. In the case of food and agriculture, it can be the application of new proposals for raw material processing technology, packaging of products, new food additives, and new agricultural technologies. Innovation may lead to reducing or preventing adverse changes caused by microorganisms, oxidation of food ingredients, and enzymatic and nonenzymatic reactions, as well as ensuring safety by inhibiting the development of some pathogenic microorganisms. Change can also provide healthier and more nutritious food. The food is tastier because of the prevention of adverse qualitative changes in food composition, including organoleptic changes, and changes in the perception and pleasures from eating food. In addition, crops can be more abundant thanks to reduced exposure to diseases, adapted agricultural treatments, or higher resistance to changing weather conditions.

The above are examples of innovation in food and agriculture. However, the literature about innovation in them is still insufficiently developed compared to studies on innovation in the high-technology sectors. A general definition of innovation says that it is the introduction of change to something new. Innovation may be things, ideas, or practices that are introduced to an audience, consumers, or users. In the "Oslo Manual" (OECD, Eurostat 2005), innovations are described as the implementation of a new or significantly improved product or process, an innovative marketing method, or a new organizational method in business practices. The meaning proposed in the "Oslo Manual" indicates changes that are first developed by an organization and those imitated by other organizations. All the above types of innovation can also be found in food and agriculture.

In general, innovations in the food sector are more incremental than in other sectors. This means that they often rely on slight changes in existing products, a product's components, or processes. Incremental innovations are related to the adaptation, refinement, and enhancement 
M. Klimczuk-Kochańska, A. Klimczuk, Innovation in Food and Agriculture, [in:] P.B. Thompson, D.M. Kaplan (eds.), Encyclopedia of Food and Agricultural Ethics, Second Edition, Springer,

Dordrecht 2019, pp. 1635-1641, https://doi.org/10.1007/978-94-007-6167-4 628-1.

of existing products or processes. Radical innovations are understood as entirely new categories of products or processes and are less frequent in food and agriculture production than in other sectors. An example of radical innovation in food is aspartame, a sweetener used in many products all over the world. These rare innovations in food manufacturing are often unplanned, serendipitous results of creative processes.

For food producers and processors, innovations are seen as the primary determinants of organizational success because innovative solutions and products allow for high performance and survival of an organization on the market. From the farmer's and manufacturer's points of view, they are also essential to increase consumer attractiveness and availability of food products. Other goals include increasing production efficiency by reducing losses and improving agrifood production efficiency.

\section{Role of the Technology Push Model for Innovation in Food and Agriculture}

The food and agriculture sector is characterized by a low level of technology, and this is how it is classified (Hirsch-Kreinsen and Jacobson 2008). However, it can be stated that innovative changes in the described industry can be related to the technology push model: innovation originates from innovative technologies. There are several arguments for finding that innovations in the sector are in line with this model.

First, the products offered by the sector are very diverse, as are the producers and processors themselves. The products that agri-food sector produce can be considered, among others, from the point of view of the raw materials that are used for production (e.g., meat, fish, and fruits), product functions (e.g., functional food or nutraceuticals), the level of novelty of products (e.g., novel food and traditional food), or the used methods of production (e.g., organic or genetically modified). Furthermore, some producers use innovative methods of production based on scientific research (e.g., functional foods). There are also enterprises in the sector using traditional production methods, which cannot even be changed in any way if the producer wants to get the appropriate labeling of products delivered to the market (e.g., protected geographical indication in the European Union).

Consequently, entities operating in the agrifood sector can be divided into two groups due to the method of technology transfer necessary to manufacture innovative products. According to the scale presented by K. Pavitt (1984), there are (1) companies with the absolute scale of production and (2) those belonging to entities dominated by suppliers of technology. In the first case, the source of innovation is an organized structure of task division in which research and 
M. Klimczuk-Kochańska, A. Klimczuk, Innovation in Food and Agriculture, [in:] P.B. Thompson, D.M. Kaplan (eds.), Encyclopedia of Food and Agricultural Ethics, Second Edition, Springer,

Dordrecht 2019, pp. 1635-1641, https://doi.org/10.1007/978-94-007-6167-4 628-1.

development (R\&D) departments are often created. The same entities design, build, and manage production systems. Therefore, the products of such organizations are often very innovative, and innovations have a radical character. The second group is represented by entities that absorb technologies embodied in acquired machines and devices. Technology transfer from abroad is carried out using the mechanism of importing capital goods. The benefits of the transfer consist of increasing professional skills related to gaining access to new knowledge. Therefore, these entities do not create their innovative advantages but instead focus on the acquisition of such advantages from their suppliers. Thus, changes in technology offered by suppliers also affect technological changes in the agri-food sector. Here we deal with incremental innovations in food and agriculture.

Another phenomenon of the agri-food sector related to the technology push innovation model is industrial convergence. This means that we can observe the application of various technologies across different industries, and this process can result in new "interindustry segments" (Broring 2005). Industrial convergence can be defined as the blurring of technological and regulatory boundaries between different separate industries. Convergence offers many opportunities for new business areas, but companies must use knowledge and technologies that are not covered by their traditional knowledge. Technological progress in various fields of science creates many possibilities of increasing the added value of food products that meet the requirements of consumers. The convergence of the agri-food sector can occur with, among others, pharmaceutical, chemical, biotechnology, nanotechnology, packaging production as well as with the sector of the machine and device manufacturers (Broring 2005). Recently, the trend of using information and communications technologies (ICTs) in the agri-food sector is also prevalent. This process is evident in technical systems that use drones, sensors, and big data analytics. There are also solutions ranging from simply ordering food applications on the Internet to, for example, services based on the Internet of Things or the blockchain technology.

\section{Role of Biotechnology in Food and Agriculture Innovation}

Concerning agri-food industry, convergence can also be seen in the use of biotechnology and genetic engineering. There are opportunities for it that can provide the high technological and productive progress, provided farms and processors to such technologies (Sarkar et al. 2018; Caira and Ferranti 2016). Biotechnology has contributed to the application of solutions associated with the production intensifying path of innovation. As a result, it is possible to use 
M. Klimczuk-Kochańska, A. Klimczuk, Innovation in Food and Agriculture, [in:] P.B. Thompson, D.M. Kaplan (eds.), Encyclopedia of Food and Agricultural Ethics, Second Edition, Springer,

Dordrecht 2019, pp. 1635-1641, https://doi.org/10.1007/978-94-007-6167-4 628-1.

selected seeds, mechanization and agrochemical fertilizers, herbicides, and pesticides. It leads farmers toward specialization and monocultures in crops and breeding. Another use of environmental biotechnology is in organic agriculture to solve environmental problems, e.g., soil fertility, technogenic soil pollution, and soil salinization. The goal is to neutralize the effects of adverse human impact on the ecosystems and to popularize the idea of "feeding the soil rather than plants." Innovations may concern, among others, biological treatment of wastewater, recycling of organic wastes, biological deodorization of gases, purification of contaminated soils (bioremediation of soils), silt, settled sludge, reservoirs, restoration of soil fertility, surface-active substances, and preventing corrosion, zero tillage, as well as biological nitrogen fixation and reduction in the need for chemical fertilizers that can be achieved by cultivating legumes (Materia et al. 2015; Ociepa-Kubicka and Pachura 2017).

There are also biotechnology innovations in food additives that can be obtained by fermentation, tissue cultures, or using enzymes. Genetic engineering makes it possible to create additives, even whole products (e.g., hamburger or milk from the laboratory), which are used in food production. The products of "cellular agriculture" are chemically identical to the natural products from, for example, meat and milk. Manufacturers claimed that they have the same taste and texture.

The technology is attractive for many reasons. It could reduce the world's reliance on livestock, decrease greenhouse gas emissions, and lessen the use of traditional farming. Also, it appears that such production is more attractive from the point of view of food safety because existing livestock practices are related to antibiotic resistance, viral outbreaks, and bacterial food contamination. Moreover, products may be addressed to particular markets, such as meat with less saturated fats, milk without lactose, or eggs without cholesterol, which may be particularly necessary due to the increase in the population of people with different food allergies or obesity. It seems, however, that despite the consumer resistance, many genetically modified products may be particularly attractive, if not for everyone, at least for specific groups of consumers. For example, genetic modifications may eliminate gluten from wheat grain and lower the cholesterol in meat.

Another direction of innovation development in the food sector is the opportunity to customize both foods according to an individual's genetic makeup or nutrigenomics. Nutrigenomics as a combination of nutritional science and genomics, is a new area with high innovation potential. Scientific knowledge in the field of genomics, plant cultivation, genetic engineering, and modern medicine is combined with the goal to develop individualized 
M. Klimczuk-Kochańska, A. Klimczuk, Innovation in Food and Agriculture, [in:] P.B. Thompson, D.M. Kaplan (eds.), Encyclopedia of Food and Agricultural Ethics, Second Edition, Springer,

Dordrecht 2019, pp. 1635-1641, https://doi.org/10.1007/978-94-007-6167-4 628-1.

nutritional products for medical prophylaxis and treatment that reduce the distance between food and pharmacy. It is a consequence of the convergence of industry between the pharmaceutical and food industries leading to products such as lowering cholesterol by consuming margarine with the specific ingredients. Convergence has led to the emergence of a new sector of nutraceuticals and functional foods (Martinez 2013). Such products are not only the result of the development of innovative technologies but also the effect of the growing trend for health and well-being, which is continuously growing the sale of hybrid products, such as products lowering cholesterol.

\section{Role of the Market Pull Model for Innovation in Food and Agriculture}

The second type of driver for innovation in food and agriculture is market needs, also known as market pull. The development of new products is necessary to adopt changes to the needs of consumers (Grunert et al. 2011).

The primary determinant of innovation in food and agriculture is the resistance of consumer. This concept explains consumer response to innovative products and processes, especially their reaction to radical innovations. Usually, it occurs in the initial stages of new product or technology adoption life cycles. D.I. Padberg and R.E. Westgren (1979), however, while examining the nature of innovation in the food industry, presented the concept of consumer inertia. They hypothesized that consumers reveal a specific risk aversion regarding the choice of new food products because although they expect new products, they are counting on the fact that new products will be similar to the already known products. This means that consumers prefer changes that are incremental. This, in turn, influences patterns of consumption and the type of product innovations introduced, which often do not go hand in hand with the possibilities of technologies available on the market. Therefore, D.I. Padberg and R.E. Westgren (1979) define the concept of "redundant technology," according to which technology and food science offer numerous possibilities of changing the characteristics of a food product (e.g., taste, nutritional content, or preparation method). However, food businesses do not take full advantage of these possibilities because there are specific demand conditions on the market.

There are some consumer psychological characteristics that affect the "willingness" to innovate. There are personality traits, attitudes, previous innovative experience, perception, motivation, and beliefs. However, also very important is if the consumer may not have the ability to innovate. These characteristics are demographic variables, namely, education, income, mobility, and age. For example, a consumer whose current lifestyle is associated with 
M. Klimczuk-Kochańska, A. Klimczuk, Innovation in Food and Agriculture, [in:] P.B. Thompson, D.M. Kaplan (eds.), Encyclopedia of Food and Agricultural Ethics, Second Edition, Springer,

Dordrecht 2019, pp. 1635-1641, https://doi.org/10.1007/978-94-007-6167-4 628-1.

some food brand (e.g., Coca-Cola) is unlikely to purchase its substitutes. According to Ram (1987), compatibility denotes consistency with the consumer, traditional, and cultural values and with consumer lifestyles. Moreover, there are consumer-perceived risks that innovation can bring, such as a physical risk that can cause harm to a person, functional risk related to the situation in which innovation does not function properly, psychological risk as a result of the fear of being seen undesirably, and economic risk concerning the situation with better or cheaper version. All these determinants of consumer attitudes to innovation in food and agriculture constitute significant barriers to innovation.

In response to the above restrictions, it is essential for food producers and processors to take a consumer-driven approach. It means that the determinant of the company's and farm's activities is to meet the needs and expectations of the consumer. Regardless of eating habits and the phenomenon of consumer inertia, in developed countries, there is a definite trend in "consumers' willingness" to pay for new and improved food products. The occurrence of consumer inertia does not mean static patterns of food consumption, as they change, but this is quite slow. In fact, there are numerous factors (e.g., higher income, demographic changes, market trends, or increased access to information), which determine continuous slight changes in food consumption and lead to consumer interest in new food products.

One of the factors that radically changed consumers' behavior in the food market and influenced the ability of the consumer to innovation is disposable income. Higher disposable income means that consumer position on the market strengthened. It causes a short life cycle of products and even constant need to introduce innovation in food and agriculture. In addition, the consumer is looking for convenient products such as pre-peeled, washed, or cooked vegetables; frozen, semi-cooked products; and dinner dishes to be heated. These innovations are also the result of the increased participation of women in the workforce, so households encounter time constraints related to the preparation of meals and, consequently, perceive convenience as an essential feature of food products. Hence there is a growing willingness to pay for services included in food products. At the same time, the role of product diversity is being increased. This is the result of an increasing emphasis on quality in general, higher concern for nutritional and health properties, and food safety.

Consumers are also interested in new combinations of flavors, aromas, and product forms. The above expectations translate into new products and processes. Consumers expect products that are low fat, low calorie, no caffeine, unsweetened, low in sodium, or low in cholesterol. Therefore, there is market potential for new food products that have better nutritional and health 
M. Klimczuk-Kochańska, A. Klimczuk, Innovation in Food and Agriculture, [in:] P.B. Thompson, D.M. Kaplan (eds.), Encyclopedia of Food and Agricultural Ethics, Second Edition, Springer,

Dordrecht 2019, pp. 1635-1641, https://doi.org/10.1007/978-94-007-6167-4 628-1.

properties but retain the same functional and sensory features as traditional products. For many consumers, eating food is a sensory experience. Especially in developed economies, food is no longer considered merely as a means of satisfying physiological needs. It should instead be treated as a product of the "experience economy" that can be enjoyed through its taste, appearance, and sometimes also aroma in specially designed environments.

Because of changes in consumer needs, there is a significant flow of new or modified food products on the market. In recent years there has been an ever-increasing product proliferation that has new features, which is the result of the previously indicated issue of consumer inertia. As a result, companies minimize market risk by selling new products that are only slightly different compared to products already on the market.

On the other hand, as T. Levitt (1975) pointed out, competition on the market will increasingly concern not competing companies with what will be produced in them but rather through what will be added to such a product in the form of, for example, packaging, services, consumer advice, delivery terms, and other issues that will give added value to the consumer. For example, a favorite functional food can be given as an example of products that are often of a conventional nature, which have been added additional value. The augmented product adds value to the core product, usually exceeding customer expectations (Kotler and Keller 2013). Product differentiation often arises on the basis of product augmentation. Product differentiation, especially in the augmented level of a product, has been used extensively as a tool to capture consumers' interest. When conventional food products are becoming more diversified, some of them by incorporating sustainable product characteristics, organic food products receive a "push" to become more diversified as well. For example, further development of the organic food market and increased consumer loyalty could be achieved by adding "extra ethical" attributes to organic products and thereby enhancing their value to (some) consumers (Zander et al. 2013).

The change of consumer needs in the food market has influenced its structure and, also, resulted in the dynamic development of services related to distribution and retail trade. In this context, food safety, related to the supply chain, is of vital importance to consumers. The traditional, long food supply chain leads to a situation where it is difficult to guarantee food safety. For example, there are numerous cases of fraud in the food industry that have destroyed consumer confidence in the food supply chain, affecting the agri-food sector. Unfortunately, these scandals have significantly contributed to the destruction of the overall image of the agrifood sector in Europe. The outsourcing in the food sector leads to the extension of the supply 
M. Klimczuk-Kochańska, A. Klimczuk, Innovation in Food and Agriculture, [in:] P.B. Thompson, D.M. Kaplan (eds.), Encyclopedia of Food and Agricultural Ethics, Second Edition, Springer,

Dordrecht 2019, pp. 1635-1641, https://doi.org/10.1007/978-94-007-6167-4 628-1.

chain and brings with it the problem of trust between clients and contractors. This, in consequence, leads to a reduction of confidence in the food producer from the consumer. Short food supply chains are some innovation. This requires the strengthening of local food chains, with substantial involvement of both producers and consumers. In this way, producers can regain an active role in creating the value of such a chain and the product itself. Such a solution allows producers to shorten the path that food must go to the consumer (Ilbery and Maye 2005). Together with the growing requirements of consumers, but also those on the part of lawmakers, the traceability of the origin of products has become increasingly important. It means tracking and tracing the flow of products down and up the supply chain. These reasons for innovating may stem from the lifestyle of different consumer groups, for example, the Millennials generation that show higher demand for organic products, sold ethically and for healthy food. They become, therefore, more conscious clients. They are supported by the possibility of using mobile devices to analyze information about products or their purchases from specific, satisfying sources.

\section{Conclusion}

The innovation in food and agriculture may be simultaneously technology-driven and marketdriven. Consumers have increasing expectations for food that will be part of a healthy lifestyle. They expect products from food companies that meet their nutritional needs, which may require the producer to change product formulas or the way products are delivered. To be able to make informed choices, they also expect precise information about the nutritional value of the products and the source of their origin. For the consumer, the quality of the raw material used for production, the applied processing, storage, and distribution technologies are becoming increasingly critical. Consequently, the changes that manufacturers make should be responsible innovations. The response from food companies may be, for example, food certification and supply chains that can allow better supervision of the flow of agricultural products and raw materials "from farm to fork" and consequently allow building consumer confidence.

Governments and new regulations that abandon or allow specific production factors for innovations (e.g., new ingredients) are also some drivers for innovation in food and agriculture. They promote practices that must be responsible - especially if there are food additives in which case the processor or producer of food complies with the standards for the level of additives used. However, thanks to the law regulations, corporations have been legislated or pressured to minimize or eliminate ingredients known to be harmful, but they must feel responsible for their 
M. Klimczuk-Kochańska, A. Klimczuk, Innovation in Food and Agriculture, [in:] P.B. Thompson, D.M. Kaplan (eds.), Encyclopedia of Food and Agricultural Ethics, Second Edition, Springer, Dordrecht 2019, pp. 1635-1641, https://doi.org/10.1007/978-94-007-6167-4 628-1.

production.

\section{References}

Broring, S. (2005). The front end of innovation in converging industries: The case of nutraceuticals and functional foods. Wiesbaden: Deutscher Universitats-Verlag.

Caira, S., \& Ferranti, P. (2016). Innovation for sustainable agriculture and food production. In Reference module in food science (pp. 1-3). Elsevier: Oxford. https://doi.org/10.1016/B978-0-08-100596-5.21018-4.

Grunert, K. G., Verbeke, W., Kugler, J. O., Saeed, F., \& Scholderer, J. (2011). Use of consumer insight in the new product development process in the meat sector. Meat Science, 89(3), 251-258.

Hirsch-Kreinsen, H., \& Jacobson, D. (Eds.). (2008). Innovation in low-tech firms and industries. Cheltenham/Northampton: Edward Elgar.

Ilbery, B., \& Maye, D. (2005). Food supply chains and sustainability: Evidence from specialist food producers in the Scottish/English borders. Land Use Policy, 22(4), 331344.

Kotler, P., \& Keller, K. L. (2013). Marketing management (2nd ed.). Madison: Pearson Education.

Levitt, T. (1975). Marketing myopia. Harvard Business Review, 38(4), 45-56.

Martinez, M. G. (2013). Open innovation in the food and beverage industry. Sawston/Cambridge: Woodhead Publishing.

Materia, V. C., Pascucci, S., \& Kolympiris, C. (2015). Understanding the selection processes of public research projects in agriculture: The role of scientific merit. Food Policy, 56, 8799.

Ociepa-Kubicka, A., \& Pachura, P. (2017). Eco-innovations in the functioning of companies. Environmental Research, 156, 284-290.

OECD, Eurostat. (2005). Oslo manual: Guidelines for collecting and interpreting innovation data (3rd ed.). Paris: OECD, Eurostat.

Padberg, D. I., \& Westgren, R. E. (1979). Product competition and consumer behavior in the food industries. American Journal of Agricultural Economics, 61(4), 620.

Pavitt, K. (1984). Sectoral patterns of technical change: Towards a taxonomy and a theory. Research Policy, 13(6), 343-373.

Ram, S. (1987). A model of innovation resistance. Advances in Consumer Research, 14(1), 
M. Klimczuk-Kochańska, A. Klimczuk, Innovation in Food and Agriculture, [in:] P.B. Thompson, D.M. Kaplan (eds.), Encyclopedia of Food and Agricultural Ethics, Second Edition, Springer,

Dordrecht 2019, pp. 1635-1641, https://doi.org/10.1007/978-94-007-6167-4 628-1.

208-212.

Sarkar, S. F., Poon, J. S., Lepage, E., Bilecki, L., \& Girard, B. (2018). Enabling a sustainable and prosperous future through science and innovation in the bioeconomy at Agriculture and Agri-Food Canada. New Biotechnology, 40, 70-75.

Zander, K., Stolz, H., \& Hamm, U. (2013). Promising ethical arguments for product differentiation in the organic food sector. A mixed methods research approach. Appetite, 62, 133-142. 